\title{
A Review on the New Normal, Employee Wellbeing and the Role of HRM: A Tale of HR among the New Normal for the Employee Wellbeing
}

\author{
Kiconco Yvonne ${ }^{1} \&$ ShiMei Jiang ${ }^{1}$ \\ ${ }^{1}$ School of Economics and Management Hebei University of Technology, Tianjin, China \\ Correspondence: Kiconco Yvonne, School of Economics and Management Hebei University of Technology, \\ Tianjin China. E-mail: yvonneyvettekiconco@yahoo.com
}

Received: April 21, 2021

Accepted: June 15, 2021

Online Published: July 13, 2021

doi:10.5539/ijbm.v16n8p115

URL: https://doi.org/10.5539/ijbm.v16n8p115

\begin{abstract}
The sudden change in scenarios due to the COVID-19 pandemic has not only affected people's financial situations but also their health and wellbeing. Psychological, physical discomfort along with on and off work schedules have led to stress for both the employer and employee. Gearing pressure of competition to survive in the dying economy has led to a path for the 'New Normal' where the current situation has been accepted as Normal with new adaptations. Employees, risking their lives and leaving the so-called comfort of their homes have had to step out to join the office while others have turned their homes into offices so as to work from home. They are at high risk of infection and stressed with the changed working scenario. The most challenging phase for the employers is the well-being of their employees for the continuous and timely work progress. The Role of HR has become the most crucial factor during this pandemic. Dealing with the employees and getting the work done with the limited resources in the crisis is the most challenging task. The present paper studies the three terms- 'New Normal', 'Employee Wellbeing' and 'Role of HR' within linked perspective and provides insight based on the various researches done in this field. It has been found that employee well-being is a well-talked topic and it has been a great concern for all the HR executives for a long time. Well- being of the employee ensures mutual gain for the employee and the organization both.
\end{abstract}

Keywords: employee wellbeing, new normal, role of HR

\section{Introduction}

With the outbreak of the COVID_19 pandemic, people's lives have changed drastically, as a result this sudden change has upset the economies and the businesses world worldwide. Now more than ever employee wellbeing is very essential as the crisis of the covid-19 brings potentially lethal physical health consequences for the work forces, mental health implications - stress, fear and uncertainty - can all be equally devastating (Stephen Koss).With HR being the heart of the organization providing manpower as the fuel to any business organization, it plays a vital role in keeping the employee wellbeing within the context of work and beyond. In such a time when stepping out and going to work is a risky affair and staying at home leads to the loss of finances, the dare of starting a new shift towards the old has given birth to 'New Normal'. Bearing all these risks and employee wellbeing in mind has become the topmost priority of every organization, on the cusp of recovery, various organizations have started embanking onto the fast paced and ever changing work culture. In the midst of social distancing, quarantine and self isolation, organizations have gone through the pressures to evolve and change at every stage of Organizational cycle to meet with the new challenges and ensure the employee manpower utilization with their wellbeing as the top priority.HR being focal point of every organization in providing man power as the fuel to the company plays a vital role in keeping the employee wellbeing within the context of work and beyond.

\subsection{Research Purpose}

The purpose of this review paper is to bring out the role of HR for the employee wellbeing in this 'New Normal, which is totally new and totally abnormal' from any point of view. 


\subsection{Practical Implications}

Practically the findings from the study will be useful for the entire corporate focusing on the mutual gain in the context of employee and employer. It would also help the workforce to resume to normal working during this new normal and would highlight the vital role HR can play in synthesizing both.

\subsection{Originality/Value}

The current paper provides an insight into the New Normal and employee wellbeing by focusing on the role HR can play for the survival of Employees and employers during uncertain times case in point being the COVID-19 pandemic.

\subsection{Relevant literature review}

Wellbeing' being a well-defined general work -"is the feeling of health, happiness and wealth. It includes the sense of life satisfaction, mental health and feeling of being purposeful" (Tchiki Davis, 2019). Psychologically it is attached to the purpose of life, mastery, positivity optimism and life satisfaction (Rudel-Fitzgerald, C., Millstein \& Hippel, et al., 2019) It is generally termed as a combination of a positive affective state of happiness and functioning with optimal effectiveness in personal, professional and social life. (Deci \& Ryan, 2008; Huppert, 2009).

In the workplace well-being is the term directly associated with the wellbeing of the employees. It is the health and safety of the employees at the workplace or broadly it is the mental and physical well-being of employees. Well-being also extends beyond happiness and job satisfaction. Research has proved that employee health influences work behavior, performance and attendance on the job and high-performance companies know this "human-capital-driven health and work behavior equation" Mary A. Gowan.

During the covid-19 period the world economies have entered a new phase of paralysis and nothing is certain of being normal, the current scenario is becoming the new normal Tyler Cowen, 2020). The word "new normal" was first used in 2008 during the financial crisis and the term was used in the context of cautioning the economist and policymakers to believe that the industrial economy would recover and come back to their rich recent past post 2007-08 financial crisis. The word was termed as "new normal's"' Paul Grover 2009, In US the post Subprime economy meaning the subpar growth was named as New Normal (Rich Miller \& Mattew Banjamin, 2008).

Presently the new normal, during this Pandemic COVID-19, is being referred to as the changes in human behavior in adopting the current scenario as normal though being new. the crisis brings potentially lethal physical health consequences for our work forces. But its mental health implications - stress, fear and uncertainty - can be equally devastating.(Stephen Koss).As per the anticipation of the Doctors at the University of Kanas Health System, this new normal would bring changes into the daily life of most of the people and that changes would continue as normal for long. As per the study done by various universities, the new normal has majorly hit the organizational work culture and lifestyle, keeping the work progress, production and other work at hold, organizations have born lots of losses and anticipating the unseen future, in order to beat the uncertainty every organization has started to work amidst the external crisis with the increased certainty of risk.The pandemic has centered the issue of physiological and mental health of people in Organizations and these organizations suddenly have to steer through the unprecedented and are forced to find out the solution to new challenges arising.

With the ease of lock down most of the employees are being encouraged to get back to their offices which also creates the pressure of passing the undesirable to their loved ones. Employees are also worried about their financial future as the economy is very slow to reap back the lost fortune. As per the survey by CIPD more than $2 / 5$ of the workers are worried about returning to the workplace during this pandemic, another $44 \%$ are feeling anxious about the health risks and $31 \%$ are worried about the commuting to the work place. The survey also found that $67 \%$ of the Top employers are anxious about the mental health and wellbeing of their work force as the main challenge to face (peter cheese, CIPD survey, 2020).

Employee well-being has been a major concern for the Employees for ages and always in the focus of the researchers for various reasons.HR is majorly facing challenges (Guest, 2017) as the changes at the workplace and society (Guest, 2011) threaten the wellbeing of the employee. HR people take employee well-being as the main goal of managing the workforce Peccei (2013). The performance-oriented HR practices help in job satisfaction and organizational commitment based on the wellbeing of the employee. Van De Voorde et al. (2012) and autonomy, incentive-based working, team spirit, and concerned approach of the HR helps in developing the wellbeing and trust in employees. 
With the setting of work from home to de-densify the workplace and to maintain the physical distancing, these arrangements have their side effects on the mental and physical health of the employees. (Brooks et al 2020), moreover, the loss of social connections and loneliness is the psychological painful phenomenon resulting from the unmet demand of the social and intimate wellbeing. Cacioppo et al. (2006), Murthy (2017) termed work and loneliness as a pandemic.

With the new setting of work from home or the alternate days of working in the office, it has shown the negative relation to employees affecting their commitment, behavior and performance (Ozcelik\& Barsade, 2018). Gigauri, (2020) HR needs to manage the people during crisis so as to enable work continuity and life balance. As most of the work is done remotely or on digital platforms Sheppard, (2020) the world needs to develop the skills on new digital era and HR can play a vital role in addressing the challenges faced by the people in doing so. As the digital era (Battiste, 2020) has changed the role of HR, it is time for employee maximization and work force utilization. Covid-19 has changed the work force working situation hence caused extra ordinary demands upon the HR people Carnevale, (2020). The remote working has caused stress on the employees and the HR both,as the offices have become a boundary with less privacy for the data which has become the main concern for the managers along with the wellbeing of the employees and their loved ones Giurge et al (2020).The impact of covid-19 and ongoing pandemic would be seen on the employment condition and employee wellbeing for the long time Akkerman's, (2020). Sherman (2020), One of the biggest challenges is the wellbeing of the employees as their work from home is certainly of a negative impact on the mental and psychological health of the workforce. The current scenario of working from home among the works of home along with child care in between the myriads of video calls and online meetings has put more pressure and stress on the employees than the normal 9 to 5 work routine.

So in the midst of the above said challenges employee well-being in the new normal and the role of HR becomes the critical issue. As established earlier wellbeing is related to the feel of someone concerning their health, home-life, personal and professional relations at home, and job or inhabits. At the workplace, well-being is being referred to the health and safety in regards to psychological and psychical measures and goes beyond happiness and job satisfaction as well. Beer et al. (2015). The wellbeing of an employee is not only the task of the HR but the employee itself, as it is seen that employee wellbeing and organization growth are based on mutual gain and optimistic perspective. The role of HR becomes very crucial to make the "new normal "well" for employee wellbeing'.

The researchers have proved that keeping various factors in mind the HR can contribute a lot to employee well-being. According to Sarah Short 2018, clarity of the work, responsibilities, variety of tasks, training and support, working hour's flexibility in work scheduled and fairness and transparency are the major factors affecting the well-being of the employees.

Kathryn M. and Dianne (2009) studied employee wellbeing into three perspectives- Subjective wellbeing, work. They worked on the employee well-being and found that wellbeing of the employee is directly related to the organization's wellbeing as it is linked with performance and turn over. Liyanage Chaturi (2020) connected the employee well- being with transformational leadership at the workplace and found that introducing leadership training would result in the social and psychological wellbeing of the employees. Koss Stephen (2020) encouraging the individual to take ownership of their wellbeing. The role of the HR functioning and the department is to shape up the organization's future and to take care of the health and wellbeing of the employees for the continuity of the organization (Seema, 2020). With the unfolding of the pandemic, it became compulsory for the industry leaders and HR personnel to care about the well-being of physical, psychological, and social morale of the people to make them ready to embrace the opportunity and challenges side by side.

\section{Design/Methodology/Approach}

The study is based upon the various reviews and facts. The researchers have done an in depth review of literature on the new normal, employee well-being and the Role of HR. The articles, blogs and the LinkedIn posts on employee well-being and the HR role, new normal and pandemic were also reviewed to analyze the content of the posts and the most relevant literature out of it.

\subsection{Research Methodology}

As the paper is based on the review of literature, so the author has used two-way approaches to find out the most relevant findings based on the various literature available on the academic and social platforms. Firstly, the author has reviewed various research papers based on the keywords and found out the most relevant trends and findings of the other authors. Secondly, the author has done the descriptive analysis of the posts, blogs, and articles and the posts written by different HR experts, trend analysis and Industry leaders. 
Exploratory data analysis was used to calculate the technical features of the reviews like polarity score, word length and numbers of reviews. Feature extraction technique was used to find out the most frequently and associated terms in the context of HR role and Employee wellbeing and Pandemic, Covid-19. Figure -1 article review flowchart shows all the reviews based on any of the keywords to get the vast picture in the structured format on the word cloud. For the analysis of data, text data was cleaned by using the reprocessing in $\mathrm{R}$ programming including the removing of special characters, punctuations, or other stop words used frequently. In the next step, the text was converted in lower case and finally, the word was lemmatized in their root forms.

Table 1. Exploratory data analysis: descriptive stats

\begin{tabular}{lllll}
\hline Type & Word length & Contribution & Helpful votes & Number of Reviews \\
\hline \multirow{2}{*}{ Blogs } & 1234.272 & 56.326 & 17.751 & \multirow{2}{*}{ 74(53.62) } \\
& $(78.196)$ & $(174.807)$ & $(41.035)$ & $35(25.36)$ \\
Articles & 1534.385 & 9.000 & 2.308 & \\
& $(82.430)$ & $(11.672)$ & $(3.660)$ & $29(21.01$ \\
Linked In & 1198.303 & 7.182 & 3.927 & \\
& $(73.668)$ & $(26.486)$ & $(12.380)$ & 138 \\
Others & 3115.2 & 45.661 & 12.148 & \\
\hline
\end{tabular}

Table 1 shows the descriptive analysis along with the technical features of the reviews. Total of 138 reviews (Blogs, articles were collected. Major sources were the blogs written by different HR professionals, Writers and trend experts. The major contribution was from the Blogs of different writers and articles published on employee wellbeing.

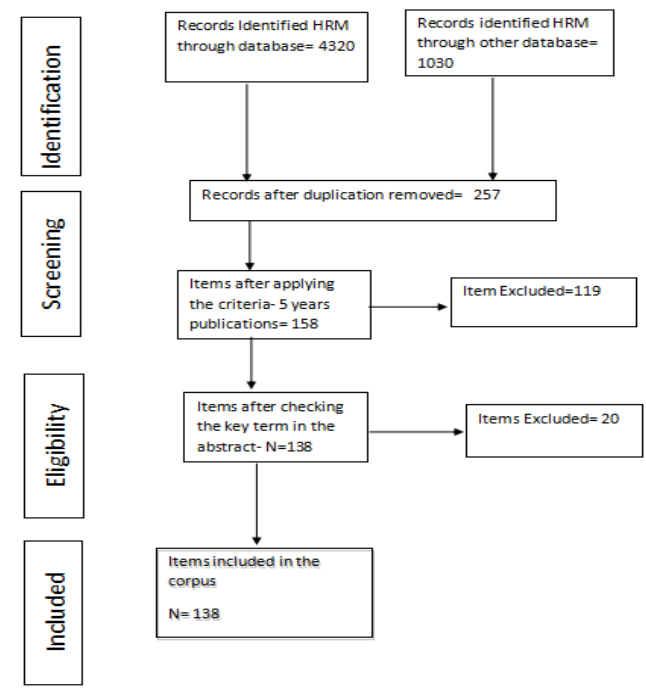

Figure 1. Article review flow chart

\subsubsection{Features Extraction}

Table 2 shows the features extracted with the help of the term associated with it. The authors have developed 4 dimensions based on the keywords of this review paper which were experienced by the HR personnel and the industry experts. 
Table 2. Feature extraction

\begin{tabular}{|c|c|c|c|}
\hline Dimension & $\begin{array}{l}\text { Name of } \\
\text { Dimensions }\end{array}$ & Key Terms & $\begin{array}{l}\text { Frequency of } \\
\text { words }\end{array}$ \\
\hline $\begin{array}{l}\text { Dimension } \\
1\end{array}$ & $\begin{array}{l}\text { Employee } \\
\text { wellbeing }\end{array}$ & happy_employee,stress_free,work_flexibility, work_autonomy, work_rewards & 172 \\
\hline $\begin{array}{l}\text { Dimension } \\
2\end{array}$ & $\begin{array}{l}\text { HR } \\
\text { Role/Organisation }\end{array}$ & $\begin{array}{l}\text { HR_leadership, HR_working, HR_support, HR-team, HR_culture, } \\
\text { organization_support, organization_leadership. organization_management, }\end{array}$ & 234 \\
\hline $\begin{array}{l}\text { Dimension } \\
3\end{array}$ & New Normal & New_habit, new_work, new_routine, new_change & 122 \\
\hline $\begin{array}{l}\text { Dimensions } \\
4\end{array}$ & Pandemic & Pandemic_stress, covid_danger, covid_safety, covid_challenges, & 74 \\
\hline
\end{tabular}

The Feature extraction shows the focus of the HR leaders and industry on the role of HR with more word counts in the reviews and the articles, while employee well-being was the second most attended area of interest. New normal being the common phenomenon was less talked and the pandemic being the negative term was less addressed issue.

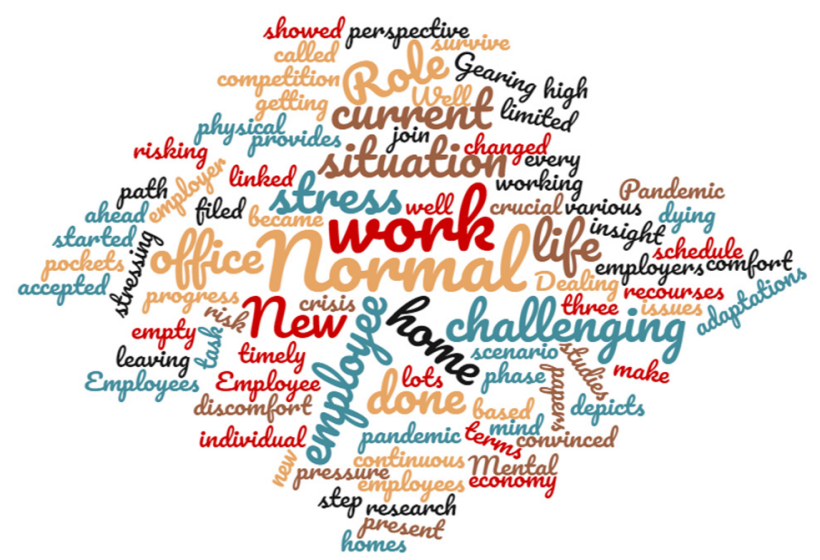

Figure 2. Word cloud

In Figure 2 the word Cloud drew based on the reviews shows that the most commonly used words during the pandemic were the "employee", "Human""organizations", " work from home", "pandemic", "new normal", " wellbeing", "challenging", "leaders", "transformational leadership"," safety", "stress", "relations" and "cautions" etc.

\section{Result and Discussion}

The findings based on the review of the literature, feature extraction and explanatory data analysis show the major trends of the HR leaders and the industry experts. It has been found that employee well-being is a well-talked issue pre-covid and it has been a great concern for all the HR executive for a long time. Well- being of the employee ensures mutual gain for the employee and the organization both. Employee well-being could be seen from the physical, psychological and social perspective and it is much needed for the continuous growth of the organization and industry. It was also established that wellbeing of an employee is not the sole task of HR but also of the employees as well. HR plays a crucial role towards employee well-being, as it is the link between the higher management and the workforce.

In conclusion therefore, it is crucial that HR should take employee concerns as top priority. Transformational leadership becomes the need of HR during a crisis like Covid-19 or any ongoing challenges in the industry and the HR can help employees to cope up with the new situations to normalize the impact of the same. The reviews of the blogs, posts, and articles also show that HR becomes the focal point at the time of crisis and good management can help the employees to adopt the new situation. The current pandemic has also shown changing working scenario and work environment has posed the question of an employee being in front of the organizations and the support in terms of flexibility in working hours, recognition, autonomy, rewards and the 
supportive environment can help the employee feel well in this new normal after this Pandemic.

\section{Limitation and Future Research Directions}

The Paper was based on the reviews of the papers earlier published on any of the keywords used in the study, Secondly, scholar has used the basic text mining so the findings are based on these reviews and text mining techniques only. Future Direction-New research could be done based on primary data taking the views employees and HR on the work situation after the pandemic and advanced techniques like- latent semantic analysis can also be used for the data mining in the future researches.

\section{References}

Akkermans, J., Richardson, J., \& Kraimer, M. (2020). The Covid-19 crisis as a career shock: Implications for careers and vocational behavior. Journal of Vocational Behavior, 119, 103-434. https://doi.org/10.1016/j.jvb.2020.103434

Akkermans, J., Richardson, J., \& Kraimer. (2020). The covid-19 crisis as a career Shock:I mlications for careers and vocational behavior. Jounal of Vocational Behaviour, 119. https://doi.org/10.1016/j.jvb.2020.103434

Beer, M., Boselie, P., \& Brewster, C. (2015). Back to the Future: Implications for the Field of HRM of the Multi stake holder Perspective Proposed 30 Years Ago. Human Resource Management, 54(3), 427-438.

Brooks, S. (2020). The Psychological Impact of Quarantine and How to Reduce It: Rapid Review of the Evidence. SSRN Electronic Journal. https://doi.org/10.2139/ssrn.3532534

Brooks, S. K. et al. (2020). The psychological impact of quarantine and how to reduce it: Rapid review of the evidence. Lancet, 395, 912-920.

Cacioppo et al. (2006). Loneliness within a nomological net: An evolutionary perspective. Journal of Research in Personality, 40(6), 1054-1085. https://doi.org/10.1016/j.jrp.2005.11.007

Carnevale, J. B., \& Hatak, I. (2020). Employee Adjustment and Well-Being in the Era of COVID-19: Implications for Human Resource Management. Journal of Business Research, 116, 183-187. https://doi.org/10.1016/j.jbusres.2020.05.037

Deci, E. L., Ryan, R. M (2008). Hedonia, eudaimonia, and well-being: An introduction. Journal of Happiness Studies, 9, 1-11. https://doi.org/10.1007/s10902-006-9018-1

Giurge, L. M., \& Bohns, V. K. (2020). Harvard Business Review. Retrieved July 30, 2020, from 3 Tips to Avoid WFH Burnout: https://hbr.org/2020/04/3-tips-to-avoid-wfh-burnout

Guerci, M., Hauff, S., \& Gilardi, S. (2019). High performance work practices and their associations with health, happiness and relational well-being: are there any trade offs? The International Journal of Human Resource Management, 1-31. https://doi.org/10.1080/09585192.2019.1695647

Guest, D. E. (2011). Human resource management and performance: still searching for some answers. Human Resource Management Journal, 21(1), 3-13. https://doi.org/abs/10.1111/j.1748-8583.2010.00164.x

Guest, D. E. (2017). Human resource management and employee well-being: towards a new analytic framework. Human Resource Management Journal, 27(1), 22-38. https://doi.org/10.1111/1748-8583.12139

Holman, D., \& Rafferty, A. (2018). The Convergence and Divergence of Job Discretion Be-teen Occupations and Institutional Regimes in Europe from 1995 to 2010. Journal of Management Studies, 55(4), 619-647. https://doi.org/10.1111/joms.12265

Huppert, F. (2009). Psychological Well-being: Evidence Regarding its Causes and Consequences. Applied Psychology: Health and Well-Being, 1(2), 137-164. https://doi.org/10.1111/j.1758-0854.2009.01008.x

Iza, G. (2020). Effects of Covid-19 on Human Resource Management from the Perspective of Digithaturi. https://doi.org/10.31435/rsglobal_ijite/30092020/7148

Liyanage, C. (2020). The Impact of Transformational Leadership on Employee Well-being: A Narrative Synthesis. Colombo Business Journal, 11(2), 24. https://doi.org/10.4038/cbj.v11i2.63

Ozcelik, H., \& Barsade, S. (2018). No employee an island: Workplace loneliness and employee performance. Academy of Management Journal, 61(6), 2343-2366. https://doi.org/10.5465/amj.2015.1066

Paauwe, J. (2009). HRM and Performance: Achievements, Methodological Issues and Prospects. Journal of Management Studies, 46(1), 129-142. https://doi.org/10.1111/j.1467-6486.2008.00809.x

Page, K., \& Vella-Brodrick, D. (2009). The 'What', 'Why' and 'How' of Employee Well-Being: A New Model. 
Social Indicators Research. https://doi.org/10.1007/s11205-008-9270-3

Parry, E., \& Battista, V. (2019). The impact of emerging technologies on work: a review of the evidence and implications for the human resource function https://doi.org/10.12688/emeraldopenres.12907.1

Peccei, R., Van De Voorde, K., \& Van Veldhoven, M. (2013). HRM, well-being and performance: A theoretical and empirical review. https://doi.org/10.1111/1748-8583.12254

Rudel-Fitzgerald. (2019). Psychological well-being as part of the public health debate? Insight into dimensions, interventions, and policy. BMC Public Health, 19, 1712. https://doi.org/10.1186/s12889-019-8029-x

Sarah Shot. (2008). What is employee wellbeing? Retrieved from https://face2facehr.com/what-is-employee-wellbeing/

Seema, F. (2020). Partner, Financial Services, Immigration and Brexit, Ertsnt \& Young LLP.

Sheppard, B. (2020). A guide to thriving HR in the post-COVID-19 workplace. Retrieved July 30, 2020, from World Economic Forum https://www.weforum.org/agenda/2020/05/workers-HR thrive-covid-19-skills/

Sheppard, B. (2020). A guide to thriving in the post-COVID-19 workplace. Retrieved from https://www.ey.com/en_gl/people/seema-farazi

Singer-Velush, N., Sherman, K., \& Anderson, E. (2020). Microsoft Analyzed Data on Its Newly Remote Workforce. Retrieved from Harvard Business Review https://hbr.org/2020/07/microsoft-analyzed-data-on-its-newly-remote-workforce

Spence, P. (2020). How COVID-19 reshapes the mental health needs of workers. https://doi.org/10.3390/ijerph17217857

Van De Voorde, K., Paauwe, J., \& Van Veldhoven, M. (2012). Employee Well-being and the HRM-Organizational Performance Relationship: A Review of Quantitative Studies. Inter-national Journal of Management Reviews, 14(4), 391-407.

\section{Copyrights}

Copyright for this article is retained by the author(s), with first publication rights granted to the journal.

This is an open-access article distributed under the terms and conditions of the Creative Commons Attribution license (http://creativecommons.org/licenses/by/4.0/). 